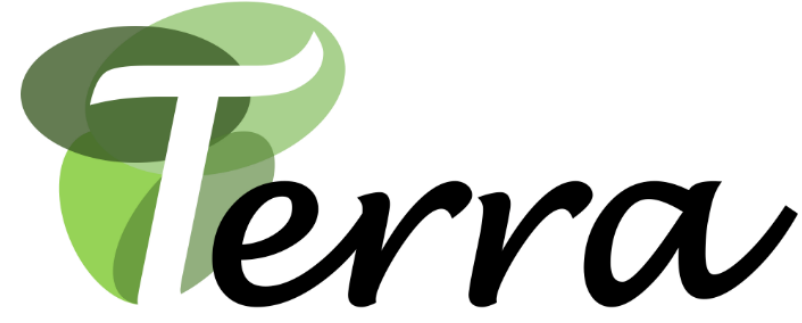

Revista de Desarrollo Local

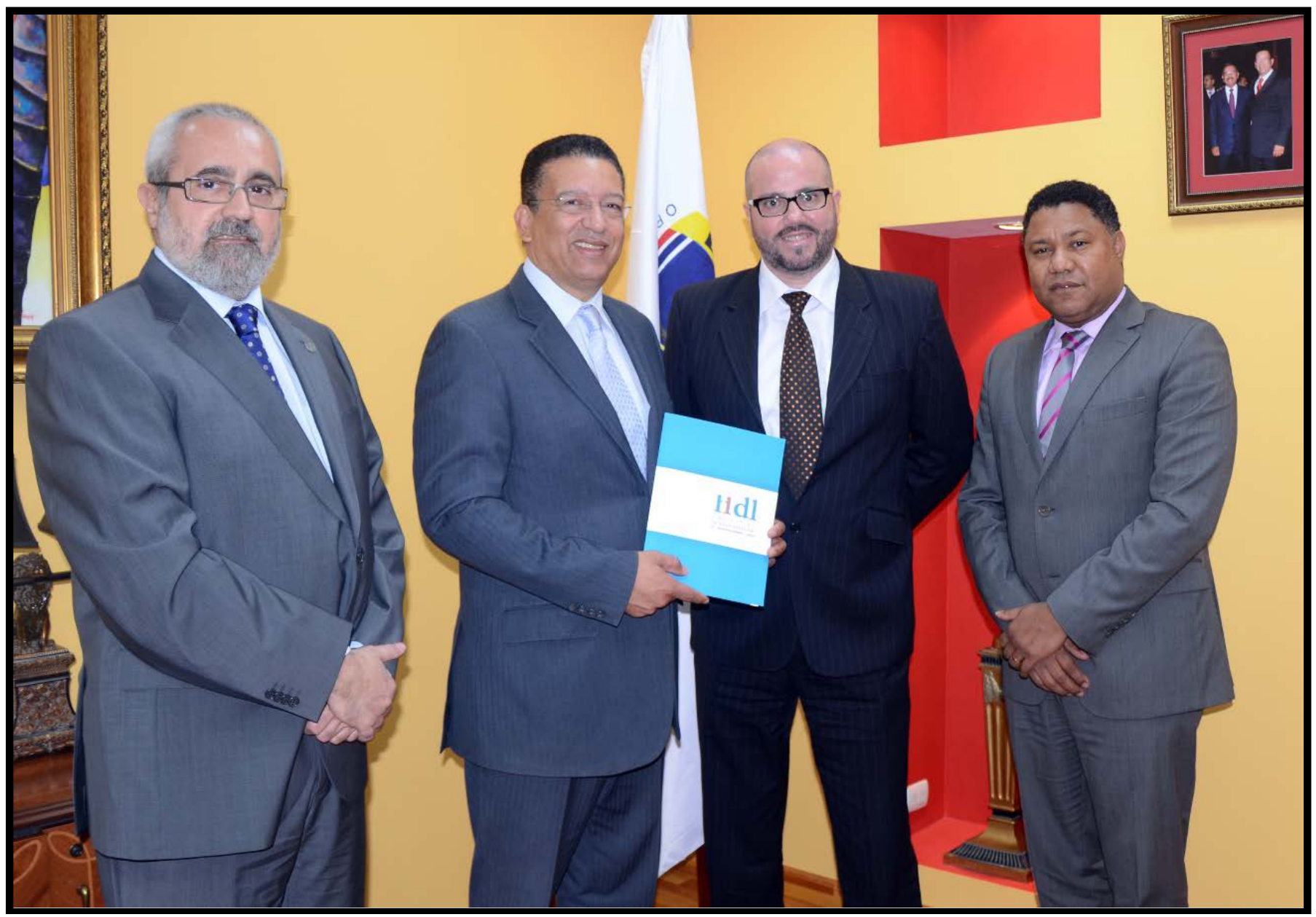

- Homenaje a Joan Noguera Tur-

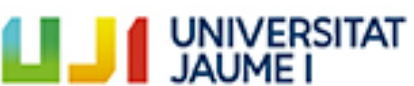

Institut Interuniversitari de Desenvolupament Loca

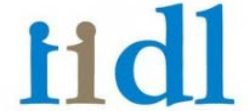

I N S I L INIERUNIVERSIIARI DE DESENYOUUPAMENT LOCAL

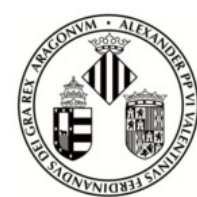

VNIVERSITAT

E VAlĖnCia 
TERRA. Revista de Desarrollo Local e-ISSN: 2386-9968

Número 8 (2021), 759-766

DOI 10.7203/terra.8.20967

IIDL - Instituto Interuniversitario de Desarrollo Local

\title{
Reseña. Una hoja de ruta para la citricultura española
}

\author{
Carles Sanchis Ibor \\ Centro Valenciano de Estudios del Riego (Universidad Politécnica de Valencia, España) \\ csanchis@hma.upv.es \\ https://orcid.org/0000-0002-8795-2922
}

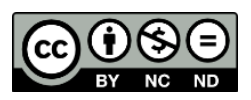

Esta obra se distribuye con la licencia Creative Commons

Reconocimiento-NoComercial-SinObraDerivada 4.0 Internacional 


\section{SECCIÓN RESEÑAS}

\section{Reseña. Una hoja de ruta para la citricultura española}

Resumen: El pasado año, tras la catastrófica campaña citrícola de 2018-2019, Enrique Moltó y José M ${ }^{a}$ García Álvarez-Coque emprendieron la coordinación de un libro colectivo que reúne contribuciones de diversos expertos en torno al futuro de la citricultura española. Se trata, sin duda, de la aproximación más completa que hasta ahora se ha publicado sobre la problemática del sector, un trabajo que se ha organizado en torno a cuatro ejes básicos: el análisis de la cadena de valor, las nuevas tecnologías, el reto de la sostenibilidad ambiental y la sanidad vegetal, y las políticas comerciales. Este libro, con un acusado acento valenciano, cubre mediante 19 capítulos las múltiples caras de un problema poliédrico, que por desgracia es visto solo en planta por los medios de comunicación y que ha recibido una atención sorprendentemente escasa por la divulgación científica. Dibuja un panorama en el que se esbozan riesgos y oportunidades, al tiempo que se atisban ganadores y perdedores. Entre estos últimos se destaca la pequeña y mediana propiedad, que a lo largo del libro va siendo señalada una y otra vez por la mayor parte de los autores. El futuro de estos campos, en manos de unos agricultores envejecidos y desmotivados, augura a medio y largo plazo un proceso de concentración de la propiedad y de integración productiva. El libro despliega buenas y malas prácticas y plantea numerosas recomendaciones para frenar el abandono en el sector. A productores y consumidores nos interesa que la tierra (y el conocimiento) se cultive, porque es bien sabido que el campo abandonado es terreno abonado para el crecimiento de malas hierbas (y peores políticas).

Palabras clave: citricultura, comercialización, estructuras agrarias, cadena de valor, agricultura de precisión, organizaciones de productores, sanidad vegetal, mercadotecnia, política agraria, agricultura ecológica.

Recibido: 25 de mayo de 2021

Devuelto para revisión: -

Aceptado: 25 de mayo de 2021

\section{Referencia / Citation:}

Sanchis, S. (2021). Reseña. Una hoja de ruta para la citricultura española. TERRA. Revista de Desarrollo Local, (8), 759-766. DOI 10.7203/terra.8.20967 


\title{
José María García Álvarez-Coque y Enrique Moltó García (coords.) UNA HOJA DE RUTA PARA LA CITRICULTURA ESPAÑOLA
}

\author{
Almería (España). Cajamar Caja Rural, 2020, 325 páginas
}

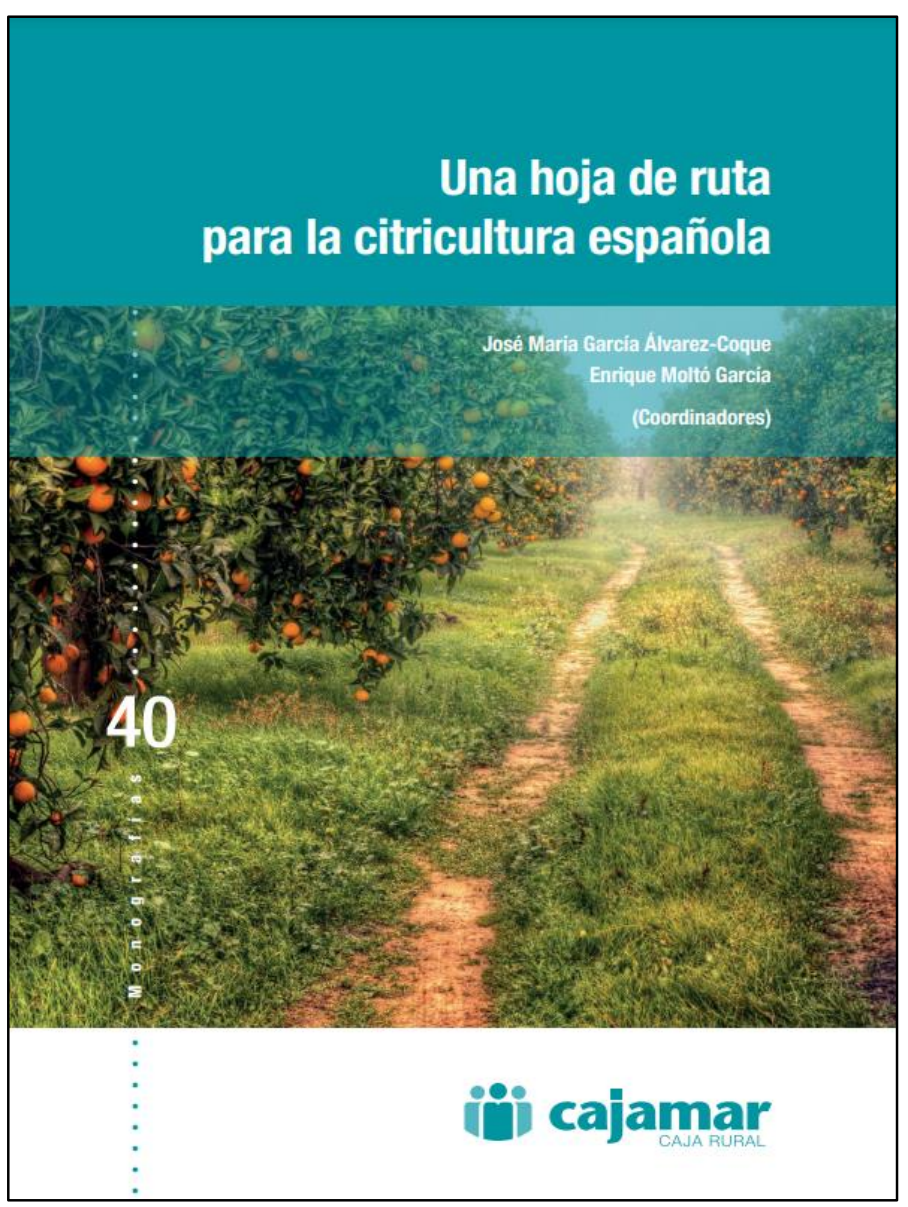

En el año 2010, el profesor Joan Noguera, a quien rendimos tributo en este volumen, publicó en el Boletín de la Asociación de Geógrafos Españoles una lúcida reflexión sobre la problemática de la citricultura valenciana. El trabajo de Joan analizaba un proceso de crisis, no exento de complejidad, que estaba generando un profundo descontento. La crisis de la naranja era objeto de debate en foros públicos y se había convertido en un lamento reiterado en las conversaciones entre agricultores. El problema venía de largo, con unos precios estancados años atrás, y se acrecentaba mentalmente por el recuerdo de una época dorada que había permitido a muchos pequeños y medianos propietarios prosperar económica y socialmente.

Una década después de la reflexión de Noguera, este descontento se ha tornado en desesperanza y se solapa con un grave problema de relevo generacional. Se han perdido 30.000 hectáreas de cultivo citrícola en los últimos 20 años y la superficie total ya es inferior a la de 1980. Son indicadores de ajuste, forzoso e involuntario, que reflejan el carácter estructural de la crisis citrícola.

Esta situación ha llevado a José María García Álvarez-Coque (Universitat Politècnica de València, UPV) y a Enrique Moltó (Institut Valencià d'Investigacions Agràries, IVIA) a liderar el trabajo colectivo. Una hoja de ruta para la citricultura española, publicada un año después, no por casualidad, de la catastrófica campaña de 2018-2019. Este libro, coral pero con reputados solistas, cuenta con 19 capítulos que permiten profundizar en las raíces de esta crisis, seleccionar el ramaje necesitado de aclareo y reconocer que puede dar lugar al cuajado de frutos en un sector maltrecho y envejecido. Los coordinadores provén el árbol del sustrato adecuado mediante un capítulo introductorio y guían su crecimiento en cuatro ejes: el primero dedicado al análisis de la cadena de valor, el segundo a las nuevas tecnologías, el tercero al reto de la sostenibilidad ambiental y la sanidad vegetal, y el último a las políticas comerciales.

Los desequilibrios de la cadena de valor se han convertido en un mantra repetido reiteradamente al dar cobertura a la información del sector agrario. El tratamiento del 
problema en los medios de masas nunca pasa de la superficie o del componente emocional del problema, ni siquiera en los reportajes más amplios. Cualquiera que quiera entender la cuestión debe acudir a la primera parte de este trabajo. Esta arranca con un trabajo de Paco Borrás que aporta numerosos datos sobre las magnitudes históricas de los mercados citrícolas, en los que los productores españoles mantienen una situación de privilegio. Tras la descripción de los principales indicadores de la evolución del sector, Borrás identifica una situación de extrema debilidad en las pequeñas y medianas explotaciones, reclama una mejor planificación de la política varietal, y apunta la necesidad de abordar estrategias de segmentación de la oferta, de fomentar la concentración del almacenamiento, la integración productiva y la prospección de mercados. GallardoCobos y Sánchez-Zamora contribuyen con un trabajo muy similar en su estructura, pero centrado en el caso de Andalucía. Efectúan un desglose de las magnitudes e indicadores de evolución del sector y llegan a conclusiones bastante similares.

El artículo firmado por Raul Compés y Alberto San Bautista es directo y esclarecedor, ahonda en estos argumentos y deja una sentencia rotunda, sin paños calientes: "una parte del sector no tiene futuro". Para llegar a esta conclusión desglosan el sector en tres tipos de fórmulas productivas. La primera la representa el grupo más heterogéneo, la citricultura independiente no asociada, compuesta por una miríada de pequeños y medianos agricultores, a tiempo completo o parcial, que utiliza los canales tradicionales de comercialización -aunque algunos pocos han optado por la venta directa en internet. En su mayoría han entrado en una espiral negativa de inversión y producción, y muchos parecen abocados al abandono o la venta de tierras. El segundo tipo es el modelo de citricultura organizada en cooperativas, con un integración horizontal y vertical parcial. Detenta una quinta parte del volumen de producción, pero atraviesa un proceso de modernización y reestructuración demasiado lento, con una excesiva fragmentación que lastra sus resultados colectivos. El tercero es la citricultura organizada en torno al sector comercial, es decir, productores que venden a empresas que proveen a la gran distribución. Estas representan sólo el $20 \%$ de la producción, pero más de dos tercios de la exportación, y cubren esta diferencia comprando cítricos a los productores no asociados. Este, apuntan los autores, es el modelo que más ha cambiado en las últimas décadas y se ha beneficiado de la creación de las organizaciones de productores (OP) en el seno de la PAC. Son, además, empresas que no han dudado en saltar al hemisferio sur para crecer y consolidarse. De los tres modelos, es el que sin duda está mejor posicionado para prosperar en los mercados nacionales e internacionales. La citricultura "tiene futuro" auguran estos autores parafraseando al ministro Planas, pero no para aquellos "anclados en estructuras productivas y comerciales del siglo pasado".

Tres capítulos posteriores comparten esta visión y apuntan estrategias de futuro. El primero lo firman José M. García Álvarez-Coque y Lorena Tudela y reclama un cambio estructural en el sector, presentando alternativas a estos dos tercios peor posicionados. Ante el enorme desafío para el pequeño y mediano productor, la única alternativa al abandono o la venta es un salto de escala. Este puede darse por tres vías: mediante el alquiler, cesión o compra, ligado a la oferta de un producto diferenciado (ecológico o ligado a variedades singulares); a través de la modernización de la fórmula cooperativista, siguiendo el modelo de otros países; o bien mediante la integración en OP de las empresas comerciales. Además, estos autores destacan la oportunidad que representan las iniciativas de gestión en común de tierras, recientemente respaldadas por la nueva ley valenciana de estructuras agrarias, las cuales abren la posibilidad de rentabilizar las explotaciones y recuperar buena parte de un suelo abandonado, pero altamente productivo. 
Más adelante, De Miguel, Caballero y Fernández-Zamudio analizan la estructura de costes de las explotaciones citrícolas, basándose en buena medida en los trabajos del extinto Departamento de Economía y Sociología Agrarias del IVIA, para reclamar principalmente, estrictos controles de calidad de las importaciones, una mejor planificación de las campañas, medidas para reducir los costes de las explotaciones y mejoras varietales. Finalmente, el capítulo de Fayos, Calderón y Moyá indaga el potencial de los mercados de exportación y las motivaciones de los consumidores, con la finalidad de trazar una estrategia de comercialización, basada en el salto de escala de los productores y en el desarrollo de acciones de marketing estratégico a escala nacional e internacional.

La segunda parte del libro se centra en el potencial de las nuevas tecnologías para mejorar diversos aspectos de la producción y comercialización de los cítricos. Aleza, del Pino y Soler abren este bloque con un trabajo sobre el desarrollo y mejora de las diferentes variedades de cítricos, un aspecto señalado en alguno de los capítulos anteriores como un nicho de oportunidad para el sector. Los tres autores afirman que, aunque pocos, todavía existen huecos comerciales que pueden ser cubiertos por mejoras varietales; subrayan la necesidad de avanzar en la estandarización del producto para atender las demandas del sector comercial; y finalmente, recomiendan el desarrollo de nuevas variedades como estrategia a seguir por investigadores y productores. De entre ellas, se destacan las pigmentaciones mediante licopenos o antocianos, las cuales resultan muy atractivas para algunos consumidores y ya están funcionando bien en mercados como el italiano o el norteamericano.

Ibáñez, Terol y Talón sintetizan en su capítulo las investigaciones recientes en el uso de herramientas genómicas, que pueden resultar clave en un futuro inmediato para mejorar las producciones, en términos cualitativos y cuantitativos, pero que además van a servir de guía para poder servir la trazabilidad de la fruta. Chueca, Mateu, González-González, Castro, Martín-Górriz y Torregrosa aportan una descripción de la maquinaria que se está empleando con éxito en diversas explotaciones para mecanizar operaciones de recolección, poda o aplicación de tratamientos fitosanitarios. González-González, Chueca, Cubero y Blasco siguen un esquema similar centrado en este caso en las tecnologías electrónicas y de información para detectar plagas o enfermedades, identificar deficiencias nutricionales o monitorizar la hidratación del arbolado. Su trabajo refleja el potencial del reciente salto tecnológico tanto en términos de sensores -cámaras multiespectrales, espectrales o térmicas-como de plataformas -drones, satélites. Es la vanguardia de la agricultura de precisión, que va asociada también a una creciente intensificación de los patrones de cultivo, de la que se ocupan Arenas-Arenas, RomeroRodríguez y Hervalejo en otro capítulo, primando aquellas prácticas de menor impacto sobre el medio natural.

Este segundo bloque constituye un importante esfuerzo divulgativo sobre la citricultura de vanguardia. Enfatiza su potencial, pero no esconde los obstáculos para su generalización, derivados fundamentalmente del predominio de la pequeña explotación familiar. Si Aleza, del Pino y Soler advierten de las dificultades que tendrán los pequeños agricultores para incorporar nuevas variedades, reivindicando el papel de las instituciones y centros de investigación públicos para prestarles apoyo, los tres capítulos siguientes coinciden en alertar sobre la inadecuación del marco de plantación tradicional, y en muchos casos también de la edad del arbolado, para poder incorporar nuevas tecnologías que abaraten costes y prácticas intensificadoras. En definitiva, esta segunda parte del libro refuerza los argumentos esgrimidos por varios autores en la primera parte: la ventana de 
oportunidad de las nuevas tecnologías está cerrada para las pequeñas explotaciones de citricultores no asociados.

El tercer bloque reúne varios trabajos que dan respuesta a algunos de los desafíos creados por el cambio climático y la globalización, haciendo especial hincapié en las plagas y enfermedades. Son trabajos de síntesis que demuestran un buen acoplamiento de la investigación y el sector, sobre todo si se compara con la situación en otros países competidores. Es uno de los puntos fuertes de la citricultura española. El primer trabajo, de Juan G. Pérez-Pérez, Ana Quiñones y Luis Bonet despliega un conjunto de técnicas de vanguardia que, más allá de la citricultura, se están aplicando en los regadíos más innovadores. El texto repasa someramente las características del riego de precisión en cítricos, el uso de nuevos diseños hidráulicos, el goteo subterráneo, el riego deficitario y el riego con aguas de baja calidad, incluyendo las prácticas de fertilización asociados a estos.

Barbé y otros seis autores del IVIA se ocupan de las enfermedades que afectan a la citricultura. El texto comienza reconociendo el éxito del programa de Mejora Sanitaria de Cítricos iniciado en 1975, el cual ha asegurado al sector una situación de privilegio a escala internacional. Describe las bacterias, hongos y virus que podrían comprometer el futuro de la citricultura española y efectúa una serie de recomendaciones que van desde un control fronterizo efectivo, a campañas formativas, fomento de la investigación y planificación de prospecciones. Urbaneja y otros seis investigadores abordan en otro capítulo el control de plagas, describiendo métodos de control biológico, infraestructuras ecológicas, semioquímicos (feromonas y otros atrayentes) y fitoseidos. Apuntan al huanglongbing (HLB) o greening como principal riesgo actual, debido a la detección reciente, en el noroeste de la Península Ibérica de su vector, la psila africana (Trioza erytreae). Por su parte, Lluís Palou se ocupa en otro capítulo de los tratamientos poscosecha, desplegando una panoplia de alternativas a los fungicidas convencionales. El bloque lo cierra el trabajo de Alfons Domínguez-Gento sobre la producción ecológica en citricultura, con un planteamiento descriptivo de la situación, regulación y potencial de un sector atrasado comparativamente a otras producciones y países, singularmente respecto a la citricultura italiana.

Finalmente, el cuarto bloque del libro vuelve a centrarse sobre aspectos socioeconómicos, en tres trabajos que abordan cuestiones relacionadas con las políticas comerciales y la regulación del sector. Tomás García Azcárate y Víctor Martínez Gómez firman el primero de los tres, en el que examinan los acuerdos de la Unión Europea con nuevos competidores en el mercado citrícola mundial, bien en el ámbito Mediterráneo principalmente Marruecos-, en el espacio Mercosur, o en África meridional (República Sudafricana). Los dos autores escrutan las debilidades y fortalezas del sector productivo de estos países y reflexionan sobre la complicada complementariedad de las producciones de los dos hemisferios, ante un creciente problema de solape temporal de sus campañas. Insisten en la creciente marginalidad de las pequeñas explotaciones ante el salto tecnológico y los mercados globales, y reclaman rigor productivo y comercial.

José Miguel Ferrer aborda el potencial de las OP de frutas y hortalizas. Describe un modelo que, pese a su potencial, presenta ciertas deficiencias en España, debido al excesivo número y escaso tamaño de las $\mathrm{OP}$-que se está corrigiendo espontáneamentey a la sobrecarga burocrática. Ferrer concreta recomendaciones para mejorar la estructura de unos organismos que la UE creó para agilizar la cadena de comercialización, pero que todavía no es capaz de ofrecer un diferencial de rentabilidad que compense a la mayoría de productores. El libro lo cierra un capítulo que analiza la legislación vigente sobre la cadena alimentaria, firmado por Javier Guillem, el que se subraya que la legislación 
europea exhorta a los países miembros a regular toda la cadena alimentaria. El texto sugiere una larga lista de reformas reglamentarias, entre las que figuran medidas destinadas a reforzar el papel de las OP para concentrar la oferta, mejorar la trazabilidad de la fruta y sus precios, y perseguir los acuerdos oclusivos y la venta a pérdidas cuando va en detrimento del productor.

Si la lectora o lector ha llegado hasta el final de esta larga relación de capítulos, habrá podido comprobar que este libro es, sin duda, la aproximación más completa que hasta ahora se ha publicado sobre la problemática de la citricultura española. El trabajo, con un acusado acento valenciano, cubre las múltiples caras de un problema poliédrico, que por desgracia es visto solo en planta por los medios de comunicación y que ha recibido una atención sorprendentemente escasa por la divulgación científica. En este sentido, hay que agradecer a Cajamar el esfuerzo que desarrolla desde hace unos años en la publicación (de acceso abierto en digital) de este tipo de trabajos, que cumplen una función fundamental en una cadena de conocimiento que probablemente tiene tantas carencias como la agroalimentaria.

El libro es, como promete el título, una hoja de ruta a tomar en cuenta por el sector y los decisores políticos, pero para llegar a ello efectúa en cada epígrafe un riguroso diagnóstico que justifica las propuestas formuladas. Dibuja un panorama en el que se esbozan riesgos y oportunidades y se atisban ganadores y perdedores. Entre estos últimos se destaca la pequeña y mediana propiedad, que a lo largo del libro va siendo señalada una y otra vez por la mayor parte de los autores. El futuro de estos campos, en manos de unos agricultores envejecidos y desmotivados, augura a medio y largo plazo un proceso de concentración de la propiedad y de integración productiva. Pero por el camino probablemente vamos a ver parcelas abandonadas. Que sean muchas o pocas depende, en buena medida, de la aplicación y seguimiento de esta hoja de ruta. A productores y consumidores nos interesa que la tierra se cultive, porque es bien sabido que el campo abandonado es terreno abonado para el crecimiento de malas hierbas (y peores políticas).

Carles Sanchis Ibor

Centro Valenciano de Estudios del Riego, Universidad Politécnica de Valencia (España)

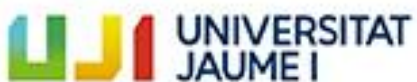

Institut Interuniversitari de Desenvolupament Local
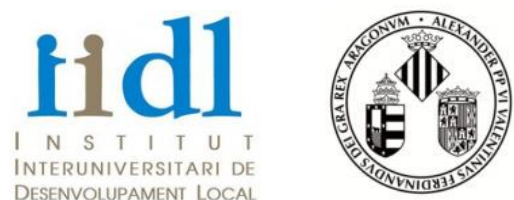

VNIVERSITAT (E) VAlÈnCia 